BMJ Open Sport \& Exercise Medicine

\title{
Comparison of baseline and postconcussion SCAT3 scores and symptoms in varsity athletes: an investigation into differences by sex and history of concussion
}

\author{
Johanna M Hurtubise, ${ }^{1,2}$ Cindy E Hughes, ${ }^{2,3}$ Lauren E Sergio, , ,2,4 \\ Alison K Macpherson ${ }^{1,2}$
}

To cite: Hurtubise JM, Hughes CE, Sergio LE, et al. Comparison of baseline and postconcussion SCAT3 scores and symptoms in varsity athletes: an investigation into differences by sex and history of concussion. BMJ Open Sport \& Exercise Medicine 2018;4:e000312. doi:10.1136/ bmjsem-2017-000312

Accepted 9 February 2018

\section{ABSTRACT}

Objective To investigate the use of the Sport Concussion Assessment Tool 3 (SCAT3) as an assessment tool in the varsity population, as well as the effects of sex and concussion history on both baseline and postconcussion scores.

Methods A comparison between baseline and postconcussion SCAT3 scores of varsity level athletes was conducted through retrospective chart review. Differences in both baseline and postconcussion scores were further analysed by sex and history of concussion.

Results The only clinically significant change on the SCAT3 elicited by a concussion was that of self-reported symptoms. There were no clinically significant differences based on sex or history of concussion.

Conclusion The SCAT3 in its entirety may not be useful in this population. Additional research on sociocultural and sport aspects that may be affecting symptom reporting in this population is needed.

\section{INTRODUCTION}

Concussion affects an estimated 3.8 million Americans each year. ${ }^{1}$ To better assess sport concussions, the Concussion in Sport Group ${ }^{2}$ integrated and modified existing concussion assessment instruments into a standardised tool. The original Sport Concussion Assessment Tool $(\mathrm{SCAT})^{2}$ has since been modified and redefined as the SCAT3 and has been one of the most widely used assessment tools for sport concussion. ${ }^{34}$ The SCAT3 consists of multiple components including symptom, cognitive, balance and coordination assessments. Each of these components have shown adequate reliability, sensitivity and specificity. ${ }^{15-7}$ Conversely, recent research using the SCAT3 on the athletic population has indicated that symptom reporting is the only significant component. However, this study only examined youth soccer players. ${ }^{8}$ To our

\section{What are the new findings?}

- After concussion, the only clinically significant change on the Sport Concussion Assessment Tool 3 (SCAT3) in varsity athletes is that of self-reported symptoms.

- Neither sex nor history of concussion had clinically significant effects on baseline or postconcussion SCAT3 scores.

How might it impact on clinical practice in the near future?

Clinicians should be aware that symptom reporting is the more important aspect of the SCAT3 in this population. In addition, symptom reporting does not differ by sex.

knowledge, the SCAT3 as a whole has not yet been investigated, in both baseline and postconcussion scores, in the university athlete population across a variety of sports.

Studies looking at both the SCAT $^{9} 10$ and SCAT2 $^{9} 1112$ observed baseline differences based on sex and previous concussion. Women report higher baseline symptoms ${ }^{911} 1314$ and higher cognitive scores, ${ }^{9} 121415$ while differences based on the presence of a previous concussion have been controversial. Some researchers have indicated that those with a history of concussion report higher baseline symptoms ${ }^{9}$ and perform better on cognitive assessments ${ }^{15}$ compared with those with no previous concussion. Others found no differences in baseline measures. ${ }^{14}$ These findings of baseline differences have not been repeated with the most recent version of the SCAT3.

The purpose of this study was twofold. First, we investigated the use of the SCAT3 as an 
acute concussion assessment tool in the varsity population by comparing preconcussion and postconcussion scores. Second, we sought to replicate previous findings from both the SCAT and SCAT2 of normative baseline differences between sex and history of concussion. We hypothesised that there would be a significant change in baseline to postconcussion scores in each component of the SCAT3, thereby validating the SCAT3 as a concussion assessment tool for collegiate athletes. We postulated that women would have a higher baseline symptom score as well as a higher cognitive score compared with men. The effects of a concussion history on baseline values are exploratory in nature due to the previous conflicting results.

\section{METHODS \\ Design}

A retrospective chart review design was used in this study and ethics was approved by York University. Subjects included in this study were varsity athletes treated at the York University Gorman/Shore Sport Injury Clinic. All athletes were required to complete a baseline SCAT3 prior to the start of their respective seasons. Baseline testing was conducted by either a Certified Athletic Therapist $(\mathrm{CAT}(\mathrm{C}))$ or an Athletic Therapy Certification Candidate. All Certification Candidates completed training in SCAT3 administration by a CAT (C) prior to conducting baseline testing to ensure consistency.

\section{Sport Concussion Assessment Tool 3}

The SCAT3 represents a revised version of the SCAT2 and the original SCAT, and consists of three primary components: (1) Symptom Inventory, (2) Sideline Assessment of Concussion (SAC) ${ }^{16}$ and (3) balance and coordination. ${ }^{1718}$ The Symptom Inventory consists of 22 commonly reported symptoms, which are self-rated on a 7-point Likert scale from 0 (no issue) to 6 (severe). Both the number of symptoms (maximum 22) and a symptom severity score (sum of all reported symptoms, maximum 132) are recorded. SAC (maximum score 30) measures cognitive ability over four subdomains, including orientation (maximum 5), immediate memory (maximum 15), delayed recall (maximum 5) and concentration (maximum 5). A higher SAC score indicates higher cognitive ability. Balance is measured through the modified Balance Error Scoring System (m-BESS), incorporating three $20 \mathrm{sec}$ tests of different stances on a firm ground. Deviation from the stance is counted as an error, up to a maximum of 10 errors per stance (maximum 30 total). The SCAT3 incorporated a tandem gait ${ }^{18}$ which is a timed $3 \mathrm{~m}$ heel-to-toe walk, where quicker times indicate superior balance (measured as time in seconds). The final component, coordination, looks at the ability to perform five finger-to-nose movements with accuracy for $4 \mathrm{sec}$ and is scored as yes $(1 / 1)$ or no $(0 / 1)$. Note that there is now a SCAT $5{ }^{19}$ available for use, however continues to include all of the aforementioned components.

\section{Participants}

From 1 August 2013 to 31 December 2016, there were 151 concussions recorded. Athletes who had a mechanism of injury and one sign or symptom were suspected of having a concussion and removed from play, as per current international standards. ${ }^{3}$ A postconcussion SCAT3 was performed by either a CAT $(\mathrm{C})$ or Certification Candidate and was followed up with a formal diagnosis by a Sports Medicine Physician (Canadian Academy of Sport and Exercise Medicine). Data were excluded from this study if the postconcussion SCAT3 was done greater than 48 hours postinjury, if a baseline SCAT3 was not completed or if the concussion represented a repeat concussion within the same year. A total of 88 concussions were included in this analysis. Aspects of the SCAT3 that were incomplete were counted as missing, but included in the overall analysis. Descriptive information, including sex and number of previous concussions, were obtained from self-report on the baseline SCAT3.

\section{Statistical analysis}

In the first analysis, outcome measures included all SCAT3 scores: number of symptoms, symptom severity, SAC score, orientation, immediate memory, concentration, delayed recall, m-BESS error score, tandem gait and coordination. In a subsequent analysis, each of the 22 symptoms reported were examined. All measures were positively skewed and not normally distributed; therefore non-parametric tests were used. Wilcoxon signed-rank tests were conducted in order to compare baseline SCAT3 scores to postconcussion scores and to compare each baseline symptom to each postconcussion symptom. In the second analysis, both baseline and postconcussion scores and symptoms were analysed based on sex (male, female) and previous concussion (yes, no) with a MannWhitney U test.

Significance was set a priori at $\mathrm{p}<0.05$. All statistical analyses were performed using SPSS V.24 statistical software.

\section{RESULTS}

Of the 88 analysed concussions (45 men, mean age 19 years $)$, the majority $(n=60,68.2 \%)$ had the follow-up SCAT3 performed on the same day as the incident. Thirty-eight $(43.2 \%)$ reported a history of at least one previous concussion at baseline testing. Of these, $52.6 \%$ were men and $47.4 \%$ were women; this did not differ significantly $\left(\chi^{2}=0.060, p=0.807\right)$. Of note, those with a previously reported concussion were significantly older than those with no reported history (mean $=20.0$ years, mean $=18.8$ years, respectively; $\mathrm{t}=-3.58, \mathrm{p}<0.001)$. See table 1 for participant demographics.

A Wilcoxon signed-rank test showed that the number of symptoms reported postconcussion was significantly higher than those reported at baseline $(\mathrm{Z}=-8.001$, $\mathrm{p}<0.001, \mathrm{r}=0.6$ ), with the median being 0 and 11 for baseline and postconcussion scores, respectively. 
Table 1 Distribution of age and sex among concussed varsity athletes with and without prior concussion

\begin{tabular}{llll}
\hline & $\begin{array}{l}\text { Previous } \\
\text { concussion }(\mathbf{n})\end{array}$ & $\begin{array}{l}\text { No history of prior } \\
\text { concussion }(\mathbf{n})\end{array}$ & Total (N, \%) \\
\hline Male & 20 & 25 & $45(51.1)$ \\
Female & 18 & 25 & $43(48.9)$ \\
& $38(43.2)$ & $50(56.8)$ & 88 \\
Age & $20.0 \pm 1.70$ & $18.8 \pm 1.26$ & $19.3 \pm 1.57$ \\
\hline
\end{tabular}

Furthermore, a concussion was associated with a higher score in the severity of the reported symptoms $(\mathrm{Z}=-7.954, \mathrm{p}<0.001, \mathrm{r}=0.6)$, with the baseline median score of 0 and the postconcussion score of 23. In addition, there were statistically significant changes in SAC $(Z=-2.063, p<0.05, r=0.2)$, orientation $(Z=-0.306$, $\mathrm{p}<0.01, \mathrm{r}=0.02)$, delayed recall $(\mathrm{Z}=-3.472, \mathrm{p}<0.001$, $\mathrm{r}=0.3)$, BESS $(\mathrm{Z}=-2.036, \mathrm{p}<0.05, \mathrm{r}=0.2)$ and tandem gait $(\mathrm{Z}=-2.078, \mathrm{pP}<0.05, \mathrm{r}=0.2)$. However, these were not clinically significant as median scores were similar (see table 2$)$. Moreover, $69(78.4 \%)$ had no change in the orientation score, and only half $(\sim 50 \%)$ showed declines in SAC, delayed recall, BESS and tandem gait scores. In fact, $35 \%$ showed improved SAC scores and $31.8 \%$ demonstrated improved tandem gait scores. A concussion was not associated with a change in immediate memory, concentration or coordination.

The 22 symptoms of the Symptom Inventory, which are ranked from 0 (no issue) to 6 (severe), were investigated further. All symptoms had a statistically significant change in severity from baseline to postconcussion, except for trouble falling asleep $(\mathrm{Z}=-1.232,=0.218)$. However, less than $50 \%$ of the participants reported an increase in severity in the following symptoms: blurred vision, balance problems, sensitive to light, sensitive to noise, confusion and drowsiness. Less than 35\% reported increases in severity in vomiting/nausea, difficulty remembering, more emotional, irritability, sadness and nervous/anxious. The majority of participants reported a symptom of headache $(84.1 \%)$, pressure in head $(80.5 \%)$, don't feel right $(70.5 \%)$ and feeling slowed down $(66 \%)$ (table 2).

\section{Sex}

At baseline, SCAT3 scores between men and women differed significantly on SAC score $(\mathrm{Z}=-2.391, \mathrm{p}<0.05$, $\mathrm{r}=0.3)$, orientation $(\mathrm{Z}=-1.990, \mathrm{p}<0.05, \mathrm{r}=0.2)$ and delayed recall $(\mathrm{Z}=-3.322, \mathrm{p}<0.001, \mathrm{r}=0.4)$. Men had a lower median score than women (26 and 27, respectively) on the SAC, delayed recall ( 3 and 4 , respectively) and orientation (5 and 5 , respectively; the mean for men was 4.91 , the mean for women was 5.0). When looking at symptom reporting at baseline, a Mann-Whitney $\mathrm{U}$ test revealed a significant difference in the reported severity of neck pain $(Z=-2.110$, $\mathrm{p}<0.05, \mathrm{r}=0.2$ ). While the median score was the same for both sexes (0), $97.7 \%$ of women reported no neck pain, but only $84.4 \%$ of men reported none.
The only significant difference between men and women postconcussion was in orientation $(\mathrm{Z}=-2.281$, $\mathrm{p}<0.05, \mathrm{r}=0.2$ ) (table 3 ). Both sexes had a median of 5 ; however, women had a higher average at 4.88 compared with men at 4.62. Men had a slightly higher median of both number of symptoms and symptom severity than women. Pertaining to postconcussion symptom scores, men reported a significantly higher severity of blurred vision than women $(\mathrm{Z}=-2.429, \mathrm{p}<0.05, \mathrm{r}=0.3$; median 1.0 and 0 , respectively) and a higher severity of irritability $(\mathrm{Z}=-1.982, \mathrm{p}<0.05, \mathrm{r}=0.2$; median of 0 and 0 , respectively). A higher percentage of men $(37.8 \%)$ reported irritability as a symptom postconcussion compared with women $(16.3 \%)$.

\section{Previous concussion history}

Athletes who reported no prior history of concussion did not report statistically significant differences on the SCAT3 from those who had self-reported prior concussions at baseline. However, a higher percentage of those with no history of concussion reported zero symptoms $(60.0 \%)$ compared with those with a history of concussion $(42.1 \%)$. There was a statistically significant difference between groups in neck pain $(\mathrm{Z}=-2.602, \mathrm{p}<0.01, \mathrm{r}=0.3)$ and fatigue/low energy $(\mathrm{Z}=-2.415, \mathrm{p}<0.05, \mathrm{r}=0.3)$. With neck pain, while both groups had the same median score $(0), 18.4 \%$ of those with a previous concussion reported this as a symptom compared with $2.0 \%$ of those with no prior history. Similarly, with fatigue/low energy, $39.5 \%$ of those with a history of concussion reported this symptom compared with $18 \%$ of those with no reported history.

Similarly to baseline, in the postconcussion scores, there were no statistically significant differences between groups. Those with a history of concussion had a lower median number of symptoms (9.0) and severity of symptoms (22.5) compared with those with no history of concussion (11.5 and 23.0, respectively). There were no significant differences in symptoms or symptom reporting between those with a history of previous concussion and those without on any of the symptoms postconcussion. See table 4 for full results.

\section{DISCUSSION}

Differences in the self-reported symptom evaluation were the most clinically significant aspect of the SCAT3 in this population. The remaining components of the SCAT3 did not show clinically significant changes between baseline and postconcussion scores. Likewise, differences based on sex or previous concussions were not clinically significant. However, importantly, those with a history of concussion had a higher median number and severity of symptoms at baseline, yet lower median scores in the postconcussion SCAT3.

\section{Which components of SCAT3 provided the most valuable information?}

Only the Symptom Inventory revealed clinically significant differences between baseline and postconcussion scores in 
Table 2 Median scores for the SCAT3 components and 22 symptoms reported at both baseline and postconcussion

\begin{tabular}{|c|c|c|c|c|}
\hline & \multirow{2}{*}{$\begin{array}{l}\text { Baseline } \\
\text { Median }\end{array}$} & \multirow{2}{*}{$\begin{array}{l}\text { Postconcussion } \\
\text { Median }\end{array}$} & \multicolumn{2}{|l|}{ Wilcoxon signed-rank sum test } \\
\hline & & & Frequency of negative change (\%) & $\mathbf{z}$ \\
\hline Number of symptoms & 0 & 11 & 95.5 & $-8.001^{\star \star \star}$ \\
\hline Symptom severity & 0 & 23 & 95.5 & $-7.954^{\star \star \star}$ \\
\hline Headache & 0 & 3 & 84.1 & $-7.526^{\star \star \star}$ \\
\hline Pressure in head & 0 & 2 & 80.5 & $-7.320^{\star \star *}$ \\
\hline Neck pain & 0 & 1 & 51.1 & $-5.718^{\star \star \star}$ \\
\hline Nausea/vomiting & 0 & 0 & 32.2 & $-4.409^{\star \star \star}$ \\
\hline Dizziness & 0 & 1 & 62.5 & $-6.224^{\star \star \star}$ \\
\hline Blurred vision & 0 & 0 & 38.6 & $-5.008^{\star * \star}$ \\
\hline Balance problems & 0 & 0 & 39.8 & $-4.646^{\star \star \star}$ \\
\hline Sensitivity to light & 0 & 1 & 46.6 & $-5.263^{\star \star \star}$ \\
\hline Sensitivity to noise & 0 & 0 & 38.6 & $-4.798^{\star \star \star}$ \\
\hline Feeling slowed down & 0 & 2 & 65.9 & $-6.621^{\star \star \star}$ \\
\hline Feeling in a fog & 0 & 1 & 53.4 & $-6.044^{\star \star \star}$ \\
\hline Don't feel right & 0 & 2 & 70.5 & $-6.880^{\star \star \star}$ \\
\hline Difficulty concentrating & 0 & 1 & 52.3 & $-5.797^{\star \star \star}$ \\
\hline Difficulty remembering & 0 & 0 & 33 & $-4.282^{\star \star \star}$ \\
\hline Fatigue/low energy & 0 & 1 & 56.8 & $-5.088^{\star \star \star}$ \\
\hline Confusion & 0 & 0 & 37.5 & $-5.048^{\star * *}$ \\
\hline Drowsiness & 0 & 1 & 44.3 & $-5.065^{\star \star \star}$ \\
\hline Trouble falling asleep & 0 & 0 & 15.9 & $-1.232^{\mathrm{NS}}$ \\
\hline More emotional & 0 & 0 & 33 & $-3.181^{\star \star \star}$ \\
\hline Irritability & 0 & 0 & 26.1 & $-3.181^{\star \star \star}$ \\
\hline Sadness & 0 & 0 & 25.3 & $-3.577^{\star \star \star}$ \\
\hline Nervous/anxious & 0 & 0 & 30.7 & $-2.470^{\star}$ \\
\hline SAC & 27 & 26 & 57 & $-2.063^{*}$ \\
\hline Orientation & 5 & 5 & 18.2 & $-3.012^{\star *}$ \\
\hline Immediate memory & 15 & 15 & 21.6 & $-0.328^{\mathrm{NS}}$ \\
\hline Concentration & 3.5 & 4 & 35.2 & $-0.306^{\mathrm{NS}}$ \\
\hline Delayed recall & 4 & 3 & 53.5 & $-3.472^{\star \star \star}$ \\
\hline m-BESS & 3 & 4 & 52.6 & $-2.036^{\star}$ \\
\hline Tandem gait & 10.2 & 11.4 & 54.5 & $-2.078^{\star}$ \\
\hline Coordination & 1 & 1 & 9.4 & $-1.291^{N S}$ \\
\hline
\end{tabular}

Wilcoxon signed-rank sum test results.

${ }^{\star} \mathrm{P}<0.05,{ }^{* *} \mathrm{p}<0.01,{ }^{* * *} \mathrm{p}<0.001$.

m-BESS, modified Balance Error Scoring System; NS, non-significant; SAC, Sideline Assessment of Concussion; SCAT3, Sport Concussion Assessment Tool 3.

the collegiate athlete population, while all other components in the SCAT3 had no clinically significant differences. These results are in accordance with a recent study by Gorman $e t a l^{8}$ in which only symptom number and severity significantly differed between youth soccer players with and without a head-related injury, while the other components of the SCAT3 did not.

The BESS has been previously validated for its use in concussion assessment with evidence of good specificity $^{717}$ and others have determined that it has only moderate sensitivity. Further, its reliability is based on the full BESS and not the modified version that is found in the SCAT3. ${ }^{50}{ }^{21}$ Additionally, variables such as fatigue, environment and poor intra-tester and inter-tester reliability have been shown to affect BESS scores. ${ }^{5622}$ This may explain the lack of clinical differences found in our study. To our knowledge, the validity of the m-BESS has not been documented. Luoto $e t a l^{21}$ found that adults with a concussion did not differ significantly from controls on the m-BESS. 
Table 3 Median scores and Mann-Whitney $U$ results for all SCAT3 components and the 22 listed symptoms at both baseline and postconcussion by sex

\begin{tabular}{|c|c|c|c|c|c|c|}
\hline & \multicolumn{3}{|l|}{ Baseline } & \multicolumn{3}{|c|}{ Postconcussion } \\
\hline & Males $(n=45)$ & Women $(n=43)$ & $\begin{array}{l}\text { Mann-Whitney } \\
\text { U test }\end{array}$ & Males $(n=45)$ & Women $(n=43)$ & $\begin{array}{l}\text { Mann-Whitney } \\
\text { U test }\end{array}$ \\
\hline & Median & Median & $\mathbf{z}$ & Median & Median & $\mathbf{z}$ \\
\hline Number of symptoms & 0 & 0 & $-0.266^{\mathrm{NS}}$ & 12 & 10 & $-1.347^{\mathrm{NS}}$ \\
\hline Symptom severity & 0 & 0 & $-0.244^{\mathrm{NS}}$ & 26 & 21 & $-1.420^{\mathrm{NS}}$ \\
\hline Headache & 0 & 0 & $-0.196^{\mathrm{NS}}$ & 3 & 3 & $-0.314^{\mathrm{NS}}$ \\
\hline Pressure in head & 0 & 0 & $-1.120^{\mathrm{NS}}$ & 2.5 & 2 & $-0.436^{\mathrm{NS}}$ \\
\hline Neck pain & 0 & 0 & $2.110^{\star}$ & 1 & 0 & $-1.441^{\mathrm{NS}}$ \\
\hline Nausea/vomiting & 0 & 0 & $-0.558^{\mathrm{NS}}$ & 0 & 0 & $-0.492^{\mathrm{NS}}$ \\
\hline Dizziness & 0 & 0 & $-0.939^{\mathrm{NS}}$ & 1 & 1 & $-1.934^{\mathrm{NS}}$ \\
\hline Blurred vision & 0 & 0 & $-0.427^{\mathrm{NS}}$ & 1 & 0 & $-2.429^{\star}$ \\
\hline Balance problems & 0 & 0 & $-1.148^{\mathrm{NS}}$ & 0 & 0 & $-0.371^{\mathrm{NS}}$ \\
\hline Sensitivity to light & 0 & 0 & $-1.349^{\mathrm{NS}}$ & 0 & 1 & $-0.528^{\mathrm{NS}}$ \\
\hline Sensitivity to noise & 0 & 0 & $-0.745^{\mathrm{NS}}$ & 0 & 0 & $-1.051^{\mathrm{NS}}$ \\
\hline Feeling slowed down & 0 & 0 & $-1.541^{\mathrm{NS}}$ & 2 & 1 & $-1.355^{\mathrm{NS}}$ \\
\hline Feeling in a fog & 0 & 0 & $-1.342^{\mathrm{NS}}$ & 1 & 1 & $-0.151^{\text {NS }}$ \\
\hline Don't feel right & 0 & 0 & $-1.723^{\mathrm{NS}}$ & 2 & 1 & $-1.897^{\mathrm{NS}}$ \\
\hline Difficulty concentrating & 0 & 0 & $-1.489^{\text {NS }}$ & 1 & 1 & $-0.075^{\mathrm{NS}}$ \\
\hline Difficulty remembering & 0 & 0 & $-0.901^{\text {NS }}$ & 0 & 0 & $-0.545^{\mathrm{NS}}$ \\
\hline Fatigue/low energy & 0 & 0 & $-0.123^{\text {NS }}$ & 1 & 1 & $-0.297^{\mathrm{NS}}$ \\
\hline Confusion & 0 & 0 & $-0.558^{\mathrm{NS}}$ & 0 & 0 & $-1.584^{\mathrm{NS}}$ \\
\hline Drowsiness & 0 & 0 & $-0.342^{\text {NS }}$ & 0 & 1 & $-0.533^{\text {NS }}$ \\
\hline Trouble falling asleep & 0 & 0 & $-0.332^{\text {NS }}$ & 0 & 0 & $-0.422^{\text {NS }}$ \\
\hline More emotional & 0 & 0 & $-0.645^{\mathrm{NS}}$ & 0 & 0 & $-1.090^{\mathrm{NS}}$ \\
\hline Irritability & 0 & 0 & $-0.526^{\mathrm{NS}}$ & 0 & 0 & $-1.982^{*}$ \\
\hline Sadness & 0 & 0 & $-0.764^{\mathrm{NS}}$ & 0 & 0 & $-0.525^{\mathrm{NS}}$ \\
\hline Nervous/anxious & 0 & 0 & $-0.612^{\text {NS }}$ & 0 & 0 & $-0.520^{\mathrm{NS}}$ \\
\hline SAC & 26 & 27 & $-2.391^{*}$ & 26 & 26 & $-1.181^{\text {NS }}$ \\
\hline Orientation & 5 & 5 & $-1.990^{\star}$ & 5 & 5 & $-2.281^{\star}$ \\
\hline Immediate memory & 15 & 15 & $-0.141^{\text {NS }}$ & 15 & 15 & $-0.759^{\text {NS }}$ \\
\hline Concentration & 3 & 4 & $-0.387^{\mathrm{NS}}$ & 4 & 4 & $-1.373^{\text {NS }}$ \\
\hline Delayed recall & 3 & 4 & $-3.322^{\star \star \star}$ & 3 & 3 & $-0.548^{\mathrm{NS}}$ \\
\hline m-BESS & 2 & 3 & $-0.934^{\mathrm{NS}}$ & 4 & 3 & $-0.620^{\text {NS }}$ \\
\hline Tandem gait & 10 & 11 & $-1.352^{\mathrm{NS}}$ & 11.3 & 11.5 & $-0.617^{\mathrm{NS}}$ \\
\hline Coordination & 1 & 1 & $-1.374^{\mathrm{NS}}$ & 1 & 1 & $-0.296^{\mathrm{NS}}$ \\
\hline
\end{tabular}

${ }^{*} \mathrm{P}<0.05,{ }^{* * *} \mathrm{p}<0.001$

m-BESS, modified Balance Error Scoring System; NS, non-significant; SAC, Sideline Assessment of Concussion; SCAT3, Sport Concussion Assessment Tool 3.

The tandem gait test was included in the SCAT3 to combat limitations of the m-BESS, but our results show that only $55 \%$ of participants had a worse score after a concussion. The finger-to-nose coordination task has good reliability in the healthy population in comparison to the single leg stance of the m-BESS; it may be a superior measure of motor dysfunction postconcussion. We, however, found no significant change from baseline to postconcussion in this measure.
While coordination, and subsequent motor skills, may be affected by concussion, we postulate that these differences may not be identified using the SCAT3 as coordination is measured simply as an ability to complete the task (yes/no). The SAC, developed to measure cognitive deficits due to concussion, has been validated for its use in concussion assessment and shows good sensitivity when tested within the first 48 hours after injury. ${ }^{16} 2324$ For example, Barr and McCrea ${ }^{24}$ looked at the SAC in 
Table 4 Median scores and Mann-Whitney $U$ test results for all SCAT3 components and the 22 listed symptoms at both baseline and postconcussion by history of concussion

\begin{tabular}{|c|c|c|c|c|c|c|}
\hline & \multicolumn{3}{|l|}{ Baseline } & \multicolumn{3}{|l|}{ Postconcussion } \\
\hline & $\begin{array}{l}\text { No concussion } \\
\text { history }(n=50)\end{array}$ & $\begin{array}{l}\text { Previous } \\
\text { concussion } \\
(\mathrm{n}=38)\end{array}$ & $\begin{array}{l}\text { Mann-Whitney } \\
\text { U test }\end{array}$ & $\begin{array}{l}\text { No concussion } \\
\text { history }(n=50)\end{array}$ & $\begin{array}{l}\text { Previous } \\
\text { concussion } \\
(\mathrm{n}=38)\end{array}$ & $\begin{array}{l}\text { Mann-Whitney } \\
\text { U test }\end{array}$ \\
\hline & Median & Median & $z$ & Median & Median & $\mathbf{z}$ \\
\hline Number of symptoms & 0 & 1 & $-1.58^{\mathrm{NS}}$ & 11.5 & 9 & $-0.245^{\mathrm{NS}}$ \\
\hline Symptom severity & 0 & 2 & $-1.589^{\mathrm{NS}}$ & 23 & 22.5 & $-0.177^{\mathrm{NS}}$ \\
\hline Headache & 0 & 0 & $-0.806^{\mathrm{NS}}$ & 3 & 2.5 & $-0.857^{\text {NS }}$ \\
\hline Pressure in head & 0 & 0 & $-1.032^{\mathrm{NS}}$ & 2 & 2 & $-1.005^{\mathrm{NS}}$ \\
\hline Neck pain & 0 & 0 & $-2.602^{\star \star}$ & 0 & 1 & $-0.483^{\mathrm{NS}}$ \\
\hline Nausea/vomiting & 0 & 0 & $-0.844^{\mathrm{NS}}$ & 0 & 0 & $-0.170^{\mathrm{NS}}$ \\
\hline Dizziness & 0 & 0 & $-0.455^{\mathrm{NS}}$ & 1 & 1 & $-1.083^{\mathrm{NS}}$ \\
\hline Blurred vision & 0 & 0 & $-0.094^{\mathrm{NS}}$ & 0 & 0 & $-1.238^{\mathrm{NS}}$ \\
\hline Balance problems & 0 & 0 & $-0.045^{\mathrm{NS}}$ & 1 & 0 & $-1.054^{\text {NS }}$ \\
\hline Sensitivity to light & 0 & 0 & $-1.162^{\mathrm{NS}}$ & 0 & 1 & $-0.239^{\mathrm{NS}}$ \\
\hline Sensitivity to noise & 0 & 0 & $-0.318^{\mathrm{NS}}$ & 0 & 0 & $-0.145^{\mathrm{NS}}$ \\
\hline Feeling slowed down & 0 & 0 & $-0.748^{\mathrm{NS}}$ & 1 & 2 & $-0.647^{\mathrm{NS}}$ \\
\hline Feeling in a fog & 0 & 0 & $-0.084^{\mathrm{NS}}$ & 1 & 0 & $-0.666^{\mathrm{NS}}$ \\
\hline Don't feel right & 0 & 0 & $-0.064^{\mathrm{NS}}$ & 2 & 2 & $-0.039^{\mathrm{NS}}$ \\
\hline Difficulty concentrating & 0 & 0 & $-0.423^{\text {NS }}$ & 1.5 & 0 & $-0.958^{\mathrm{NS}}$ \\
\hline Difficulty remembering & 0 & 0 & $-1.218^{\mathrm{NS}}$ & 0 & 0 & $-0.190^{\mathrm{NS}}$ \\
\hline Fatigue/low energy & 0 & 0 & $-2.415^{\star}$ & 1 & 1 & $-0.030^{\mathrm{NS}}$ \\
\hline Confusion & 0 & 0 & $-0.362^{\mathrm{NS}}$ & 0 & 0 & $-0.895^{\mathrm{NS}}$ \\
\hline Drowsiness & 0 & 0 & $-0.851^{\mathrm{NS}}$ & 0.5 & 1 & $-0.063^{\mathrm{NS}}$ \\
\hline Trouble falling asleep & 0 & 0 & $-1.261^{\mathrm{NS}}$ & 0 & 0 & $-0.971^{\mathrm{NS}}$ \\
\hline More emotional & 0 & 0 & $-1.141^{\mathrm{NS}}$ & 0 & 0 & $-0.210^{\mathrm{NS}}$ \\
\hline Irritability & 0 & 0 & $-1.203^{\mathrm{NS}}$ & 0 & 0 & $-0.306^{\mathrm{NS}}$ \\
\hline Sadness & 0 & 0 & $-0.401^{\mathrm{NS}}$ & 0 & 0 & $-0.497^{\mathrm{NS}}$ \\
\hline Nervous/anxious & 0 & 0 & $-1.441^{\mathrm{NS}}$ & 0 & 0 & $-0.825^{\mathrm{NS}}$ \\
\hline SAC & 27 & 27 & $-0.381^{\mathrm{NS}}$ & 26 & 26 & $-0.574^{\mathrm{NS}}$ \\
\hline Orientation & 5 & 5 & $-0.747^{\mathrm{NS}}$ & 5 & 5 & $-0.313^{\mathrm{NS}}$ \\
\hline Immediate memory & 15 & 15 & $-0.044^{\mathrm{NS}}$ & 15 & 15 & $-0.854^{\mathrm{NS}}$ \\
\hline Concentration & 4 & 3 & $-1.403^{\text {NS }}$ & 4 & 4 & $-0.070^{\mathrm{NS}}$ \\
\hline Delayed recall & 4 & 4 & $-0.140^{\mathrm{NS}}$ & 3 & 3 & $-0.930^{\mathrm{NS}}$ \\
\hline m-BESS & 3 & 3 & $-0.505^{\mathrm{NS}}$ & 4 & 4 & $-0.469^{\mathrm{NS}}$ \\
\hline Tandem gait & 10 & 11.3 & $-1.562^{\mathrm{NS}}$ & 11.3 & 11.6 & $-0.761^{\mathrm{NS}}$ \\
\hline Coordination & 1 & 1 & $-0.630^{\mathrm{NS}}$ & 1 & 1.0 & $-1.619^{\mathrm{NS}}$ \\
\hline
\end{tabular}

${ }^{*} \mathrm{P}<0.05,{ }^{* *} \mathrm{p}<0.01$.

m-BESS, modified Balance Error Scoring System; NS, non-significant; SAC, Sideline Assessment of Concussion; SCAT3, Sport Concussion Assessment Tool 3.

male high school and university football players, showing an average drop of 4 points after a concussion. However, the authors also noted low test-retest reliability, stating that the subdomains of the SAC score may be susceptible to variability over time.

The student athlete population used in our study may have a greater variability in their cognitive ability over time, potentially explaining why there were no clinically significant changes in cognitive components. Furthermore, since these were high level athletes, they may have had previous experience with the SCAT3. We suggest that these athletes may deliberately underperform at baseline in order to maintain similar cognitive score in the presence of concussion.

The significant change found in both the number of endorsed symptoms as well as symptom severity for those 
with a concussion supports previous research. ${ }^{5} 78$ 25-29 While there are many different symptom scales currently in use, all have shown an increase in symptom scores in the acute stages of concussion. ${ }^{25}$ The consistency of this result gives rise to the current diagnostic criteria in which a change in at least one sign or symptom with a mechanism for injury must be present. ${ }^{3}$ When looking at the specific symptoms reported, we found the most frequently reported symptoms after a concussion were headache, pressure in the head, don't feel right and feeling slowed down, consistent with other findings. ${ }^{28}$

\section{Sex differences}

We found no clinically significant differences in scores between men and women. Women scored higher on baseline cognitive scores including overall SAC score, orientation and delayed recall, which is consistent with previous literature. ${ }^{9} 1415$ Although these differences in cognitive scores are statistically significant, this may not translate into clinically significant differences. Furthermore, in contrast to previous research where women consistently report more symptoms at both baseline and postconcussion, ${ }^{9} 11121528$ 30-32 we found no statistically significant difference between men and women in the number and severity of symptoms. It has been proposed that women tend to endorse more symptoms due to hormonal changes during different stages of the menstrual cycle,$^{11}$ the sport environment ${ }^{3133}$ and social context. ${ }^{34}$ It has been suggested that men are often praised for playing through pain and injury and thus may hide or minimise their symptoms in an effort to return to sport sooner, whereas women are typically more concerned about their future health. ${ }^{31}{ }^{33-35}$ With the increasing knowledge about the potential detrimental effects of concussion, there may be a sociocultural shift in the reporting of concussion symptoms. This may result in men reporting either more, or the same number, of symptoms as women as seen in both our current and few previous studies. ${ }^{28} 36$

\section{Differences based on history of concussion}

Similar to previous findings, ${ }^{9}{ }^{14}$ a history of previous concussion had no significant effects on baseline SCAT3 scores. However, a greater proportion of those with a history of concussion (57.9\%) reported symptoms compared with $40.0 \%$ of those with no prior history. Although not significantly different, those with a history of previous concussion had a lower median for both number and severity of symptoms in the postconcussion SCAT3. Bruce and Echemendia ${ }^{37}$ observed similar results and suggest that those with no history of concussion are unaccustomed to the emerging symptoms, whereas those with a previous concussion may be more familiar. The authors posit that those with a history of concussion are aware that both their prior history and reported symptoms often increase the length of time before being cleared and thus minimise their symptoms in order to return to sport more quickly. These theories may help explain our findings.

\section{Limitations and strengths}

While our study reveals some important factors to consider when using the SCAT3 with the varsity population for concussion assessment, it is not without its limitations. Our study was based on retrospective chart review, therefore we could not control for outside variables; for example, comorbid injuries could impact symptom reporting. Further research is needed to better understand the sociocultural influence on symptom reporting and resolution, and it may be interesting to compare the time in their competitive season at which a concussion occurs. Other possible variables such as sport, position, previous experience with the SCAT3, learning disabilities and neurological disorders would be of interest to investigate in this population; however, a larger sample size is needed.

\section{CONCLUSION}

While the SCAT3 remains one of the most widely used tools for concussion assessment in sport, including the varsity student-athlete population, the only clinically significant change elicited by a concussion was that of self-reported symptoms. While men and women did not differ clinically on either baseline or postconcussion measures of the SCAT3, men typically reported a higher number and severity of symptoms on the postconcussion SCAT3. Similarly, there were no significant differences in symptom reporting between those with a previous concussion history and those with no previous concussion history on either the baseline or postconcussion measure. Additional research is needed in order to better understand the potential sociocultural and sport aspects that may be affecting symptom reporting in this population.

Funding statement Alison Macpherson holds a Canadian Institutes of Health Research chair (grant number: 126341).

Competing interests None declared.

Ethics approval Ethics approval from York University.

Provenance and peer review Not commissioned; externally peer reviewed.

Open Access This is an Open Access article distributed in accordance with the Creative Commons Attribution Non Commercial (CC BY-NC 4.0) license, which permits others to distribute, remix, adapt, build upon this work non-commercially, and license their derivative works on different terms, provided the original work is properly cited and the use is non-commercial. See: http://creativecommons.org/ licenses/by-nc/4.0/

(c) Article author(s) (or their employer(s) unless otherwise stated in the text of the article) 2018. All rights reserved. No commercial use is permitted unless otherwise expressly granted.

\section{REFERENCES}

1. Harmon KG, Drezner JA, Gammons M, et al. American Medical Society for Sports Medicine position statement: concussion in sport. Br J Sports Med 2013;47:15-26.

2. Mccrory P, Johnston K, Meeuwisse W. Summary and agreement statemtn of the 2nd International Conference on Concussion in Sport, Prague 2004. Br J Psychol 2005;39:196-204.

3. McCrory P, Meeuwisse WH, Aubry M, et al. Consensus statement on concussion in sport: the 4th International Conference on Concussion in Sport held in Zurich, November 2012. Br J Sports Med 2013;47:250-8. 
4. Williams RM, Welch CE, Weber ML, et al. Athletic trainers' management practices and referral patterns for adolescent athletes after sport-related concussion. Sports Health 2014;6:434-9.

5. Guskiewicz KM, Register-Mihalik J, McCrory P, et al. Evidencebased approach to revising the SCAT2: introducing the SCAT3. Br J Sports Med 2013;47:289-93.

6. Choe MC, Giza CC. Diagnosis and management of acute concussion. Semin Neurol 2015;35:29-41.

7. Giza CC, Kutcher JS, Ashwal S, et al. Summary of evidence-based guideline update: evaluation and management of concussion in sports: report of the Guideline Development Subcommittee of the American Academy of Neurology. Neurology 2013;80:2250-7.

8. Gorman M, Hecht S, Samborski A, et al. SCAT3 assessment of non-head injured and head injured athletes competing in a large international youth soccer tournament. Appl Neuropsychol Child 2017;6:364-8.

9. Zimmer A, Marcinak J, Hibyan S, et al. Normative values of major SCAT2 and SCAT3 components for a college athlete population. Appl Neuropsychol Adult 2015;22:132-40.

10. Johnston KM, McCrory P, Mohtadi NG, et al. Evidence-Based review of sport-related concussion: clinical science. Clin J Sport Med 2001;11:150-9.

11. Covassin T, Swanik CB, Sachs M, et al. Sex differences in baseline neuropsychological function and concussion symptoms of collegiate athletes. Br J Sports Med 2006;40:923-7.

12. Jinguji TM, Bompadre V, Harmon KG, et al. Sport Concussion Assessment Tool-2: baseline values for high school athletes. Br J Sports Med 2012;46:365-70.

13. Kontos AP, Elbin RJ, Schatz P, et al. A revised factor structure for the post-concussion symptom scale: baseline and postconcussion factors. Am J Sports Med 2012;40:2375-84.

14. Valovich McLeod TC, Bay RC, Lam KC, et al. Representative baseline values on the Sport Concussion Assessment Tool 2 (SCAT2) in adolescent athletes vary by gender, grade, and concussion history. Am J Sports Med 2012;40:927-33.

15. Shehata N, Wiley JP, Richea S, et al. Sport concussion assessment tool: baseline values for varsity collision sport athletes. Br J Sports Med 2009;43:730-4.

16. McCrea M, Kelly JP, Randolph C, et al. Standardized assessment of concussion (SAC): on-site mental status evaluation of the athlete. $J$ Head Trauma Rehabil 1998;13:27-35.

17. Riemann BL, Guskiewicz KM. Effects of mild head injury on postural stability as measured through clinical balance testing. J Athl Train 2000;35:19-25.

18. Schneiders AG, Sullivan SJ, Gray AR, et al. Normative values for three clinical measures of motor performance used in the neurological assessment of sports concussion. J Sci Med Sport 2010;13:196-201.

19. Mccrory P, Meeuwisse W, Dvorak J. Consensus statement on concussion in sport-the 5th international conference on concussion in sport held in Berlin, October 2016. Br J Sports Med 2017;0:1-10.

20. Finnoff JT, Peterson VJ, Hollman JH, et al. Intrarater and Interrater Reliability of the Balance Error Scoring System (BESS). Pm R $2009 ; 1: 50-4$
21. Luoto TM, Silverberg ND, Kataja A, et al. Sport concussion assessment tool 2 in a civilian trauma sample with mild traumatic brain injury. J Neurotrauma 2014;31:728-38.

22. Valovich TC, Perrin DH, Gansneder BM. Repeat administration elicits a practice effect with the balance. J Athl Train 2003;38:51-6.

23. McCrea M. Standardized mental status assessment of sports concussion. Clin J Sport Med 2001;11:176-81.

24. Barr WB, McCrea M. Sensitivity and specificity of standardized neurocognitive testing immediately following sports concussion. $J$ Int Neuropsychol Soc 2001;7:693-702.

25. Alla S, Sullivan SJ, Hale L, et al. Self-report scales/checklists for the measurement of concussion symptoms: a systematic review. $\mathrm{Br} \mathrm{J}$ Sports Med 2009;43 Suppl 1(Suppl_1):i3-12.

26. King NS, Crawford S, Wenden FJ, et al. The Rivermead Post Concussion Symptoms Questionnaire: a measure of symptoms commonly experienced after head injury and its reliability. $J$ Neurol 1995;242:587-92.

27. Lau BC, Collins MW, Lovell MR. Sensitivity and specificity of subacute computerized neurocognitive testing and symptom evaluation in predicting outcomes after sports-related concussion. Am J Sports Med 2011;39:1209-16.

28. Lovell MR, Iverson GL, Collins MW, et al. Measurement of symptoms following sports-related concussion: reliability and normative data for the post-concussion scale. Appl Neuropsychol 2006:13:166-74.

29. Randolph C, Millis S, Barr WB, et al. Concussion symptom inventory: an empirically derived scale for monitoring resolution of symptoms following sport-related concussion. Arch Clin Neuropsychol 2009;24:219-29.

30. Zuckerman SL, Apple RP, Odom MJ, et al. Effect of sex on symptoms and return to baseline in sport-related concussion. $J$ Neurosurg Pediatr 2014;13:72-81.

31. Broshek DK, Kaushik T, Freeman JR, et al. Sex differences in outcome following sports-related concussion. J Neurosurg 2005;102:856-63.

32. Dillard C, Ditchman N, Nersessova K, et al. Post-concussion symptoms in mild traumatic brain injury: findings from a paediatric outpatient clinic. Disabil Rehabil 2017;39:544-50.

33. Covassin T, Elbin RJ. The female athlete: the role of gender in the assessment and management of sport-related concussion. Clin Sports Med 2011;30:125-31.

34. Granito VJ. Psychological response to athletic injury: Gender differences. J Sport Behav 2002;25:243-59.

35. Covassin T, Elbin RJ, Harris W, et al. The role of age and sex in symptoms, neurocognitive performance, and postural stability in athletes after concussion. Am J Sports Med 2012;40:1303-12.

36. Covassin T, Schatz P, Swanik CB, Buz Swanik C. Sex differences in neuropsychological function and post-concussion symptoms of concussed collegiate athletes. Neurosurgery 2007;61:345-51.

37. Bruce JM, Echemendia RJ. Concussion history predicts selfreported symptoms before and following a concussive event. Neurology 2004;63:1516-8. 